\title{
Novel Highly Sensitive Protein Sensors Based on Tapered Optical Fibres Modified with Au-Based Nanocoatings
}

\author{
Aitor Urrutia, ${ }^{1}$ Kartheka Bojan, ${ }^{2}$ Leonel Marques, ${ }^{2}$ Kevin Mullaney, ${ }^{3}$ Javier Goicoechea, \\ Stephen James, ${ }^{3}$ Matt Clark, ${ }^{2}$ Ralph Tatam, ${ }^{3}$ and Sergiy Korposh ${ }^{2}$ \\ ${ }^{1}$ Nanostructured Optical Devices Laboratory, Electric and Electronic Engineering Department, Public University of Navarra, \\ Campus Arrosadia, 31006 Pamplona, Spain \\ ${ }^{2}$ Advanced Optics Group, Faculty of Engineering, University of Nottingham, University Park, Nottingham NG7 2RD, UK \\ ${ }^{3}$ Department of Engineering Photonics, School of Engineering, Cranfield University, Cranfield, Bedfordshire MK43 0AL, UK
}

Correspondence should be addressed to Sergiy Korposh; s.korposh@nottingham.ac.uk

Received 6 May 2016; Accepted 19 July 2016

Academic Editor: Rodolfo M. Manuel

Copyright (C) 2016 Aitor Urrutia et al. This is an open access article distributed under the Creative Commons Attribution License, which permits unrestricted use, distribution, and reproduction in any medium, provided the original work is properly cited.

\begin{abstract}
Novel protein sensors based on tapered optical fibres modified with Au coatings deposited using two different procedures are proposed. Au-based coatings are deposited onto a nonadiabatic tapered optical fibre using (i) a novel facile method composed of layer-by-layer deposition consisting of polycation (poly(allylamine hydrochloride), $\mathrm{PAH}$ ) and negatively charged $\mathrm{SiO}_{2}$ nanoparticles (NPs) followed by the deposition of the charged Au NPs and (ii) the sputtering technique. The Au NPs and Au thin film surfaces are then modified with biotin in order to bind streptavidin (SV) molecules and detect them. The sensing principle is based on the sensitivity of the transmission spectrum of the device to changes in the refractive index of the coatings induced by the SV binding to the biotin. Both sensors showed high sensitivity to SV, with the lowest measured concentration levels below $2.5 \mathrm{nM}$. The calculated binding constant for the biotin-SV pair was $2.2 \times 10^{-11} \mathrm{M}^{-1}$ when a tapered fibre modified with the LbL method was used, with a limit of detection (LoD) of $271 \mathrm{pM}$. The sensor formed using sputtering had a binding constant of $1.01 \times 10^{-10} \mathrm{M}^{-1}$ with a LoD of $806 \mathrm{pM}$. These new structures and their simple fabrication technique could be used to develop other biosensors.
\end{abstract}

\section{Introduction}

The relevance of biosensors is growing rapidly in a wide number of research fields, as well as in industrial services and biomedical applications [1]. Health, pharmaceutics, food control, and veterinary and other science sectors require the development of diverse and specific sensors. These devices may be based on different detection methods, electrical, optical, chemical, or mechanical. The optical fibre sensor is one of the most attractive biosensors, with a number of advantages such as high sensitivity, low-cost, high selectivity, light-weight, remote sensing capability, and electromagnetic immunity [2-4].

Different approaches to protein sensing based on optical fibres have been reported using long period gratings [5, 6], fibre Bragg gratings [7, 8], photonic crystal fibres [9], refractometers [10], and other optical configurations [11, 12]. Tapering of an optical fibre is one of the simplest methods for the fabrication of optical fibre sensors. Tapering provides access to the evanescent wave (EW) of the mode propagating through the tapered region, facilitating interaction with the surrounding medium and allowing the measurement of parameters such as refractive index or chemical composition.

In order to conduct selective measurements and to determine the desired analyte in a complex matrix of compounds, the optical fibre sensor requires a sensitive layer to be deposited on its surface. The performance of the optical fibre sensor depends strongly on the physical and chemical properties of the sensitive layer, such as porosity, film thickness, surface adhesion, and binding capabilities [13-15]. Control of the structure and properties of the sensitive element is a crucial point in sensor development and design.

Various deposition techniques, such as dip-and-spin coating [16], layer-by-layer (LbL) deposition electrostatic self-assembly [17], Langmuir-Blodgett deposition [18], and 
chemical and physical vapour deposition [19], have been employed for the functional coating of optical fibres. Among these techniques, the LbL technique, which is based on the alternate adsorption of polycations and polyanions onto the surface, is a powerful surface modification method. This alternate adsorption technique is still expanding its potential because of its versatility and convenience for the fabrication of nanoassembled thin films employing various organic and inorganic materials.

Tapered optical fibres have been well characterised both theoretically and experimentally [20, 21]. Recently, the use of tapered optical fibres modified with Au nanoparticles to create sensors based on the surface plasmon resonance (SPR) phenomenon attracted a lot of attention [22, 23]. Zhang et al. reported the development of a tapered optical fibre biosensor based on Au nanoparticles to create localized surface plasmon resonances (LSPR) [24]. A salinization method using 3-aminopropyltrimethoxy silane (APTMS) and 3mercaptopropyltrimethoxy silane (MPTMS) was employed for the deposition of the star-shaped Au nanoparticles onto the surface of a tapered optical fibre. The sensor showed a reasonable sensitivity to refractive index change of $1190.5 \mathrm{~nm} /$ RIU. However, the authors did not report biological sensing using the developed device. Srivastava and Gupta [25] proposed a multitapered optical fibre sensor based on a multimode optical fibre modified with Au NPs, reporting a sensitivity of $3500 \mathrm{~nm} / \mathrm{RIU}$. There are a limited number of reports where single mode tapered optical fibre sensors modified with $\mathrm{Au}$ thin films have been used for the detection of the biological compounds [26-28]. Perhaps the closest example of a biosensor based on tapered optical fibre SPR was reported by Rajan et al. [28], where the surface of the optical fibre was modified with an enzyme for pesticide detection. The sensor showed high sensitivity, with the lowest detected concentration of $1 \mu \mathrm{M}$.

The methods used for the deposition of $\mathrm{Au}$ films onto optical fibres reported so far are based on salinization or sputtering. In most cases, these devices require the use of complex dyes or chemicals for fluorescence-based detection [29], or other setups with expensive laboratory equipment. In addition, these methods do not provide the flexibility to control the structural parameters of the sensitive layer ( $\mathrm{Au}$ thin film), such as its morphology and porosity that have a significant influence on sensor performance.

In this study, we propose a novel alternative deposition method that allows these disadvantages to be overcome and that provides a means to control the porosity and morphology of the thin films. In addition, to the best of our knowledge, this is the first report of the use of tapered optical fibre sensors to detect very low protein concentrations. Au-based coatings were deposited onto nonadiabatic tapered optical fibre using two approaches: (i) a novel facile method composed of layerby-layer deposition consisting of polycation (poly(allylamine hydrochloride), $\mathrm{PAH}$ ) and negatively charged $\mathrm{SiO}_{2}$ nanoparticles (NPs) followed by the deposition of the charged $\mathrm{Au}$ NPs and (ii) the sputtering technique, which was used for comparison. The LbL deposition technique is based on the alternate deposition of oppositely charged polyelectrolytes [30] which, being a simple and systematic process, allows control of the incorporation of NPs into the thin films [31]. The $\mathrm{SiO}_{2}$ NPs endow the sensitive layer with high porosity, while the Au NPs help to increase the efficiency of the light interaction with the analyte, thus enhancing the sensitivity of the optical fibre device.

For this work, biotin and streptavidin (SV) binding was chosen as the protein sensing model. SV molecules have very high affinity for biotin, as their binding is one of the strongest noncovalent interactions in nature [32]. In a previous report, biotin was attached covalently to gold immobilized on an optoelectronic silicon transducer [33]. The biotin-SV binding process produces measurable variations in the external refractive index surrounding the tapered optical fibre and modifies the optical transmission spectra, thus acting as the sensing mechanism.

The presented devices show that not only tapered optical fibres but also the significance of coating characteristics (morphology and method) in optical fibre sensing is an important sensing platform. The light coupling properties of the tapered region, combined with appropriate and simple Au-based nanocoatings, allow the demonstration of different protein sensors with high sensitivity and very low limits of detection (LoD).

To our knowledge, this is the first time that sputtering techniques and tapered optical fibres were combined to demonstrate a protein sensing device, and furthermore protein tapered optical fibre sensors using LbL have not been reported before.

\section{Materials and Methods}

2.1. Chemical Reagents and Materials. Ethanol (99\%), tetraethyl orthosilicate (TEOS), chloroauric acid $\left(\mathrm{HAuCl}_{4}\right)$, sodium borohydride $\left(\mathrm{NaBH}_{4}\right)$, potassium carbonate $\left(\mathrm{K}_{2} \mathrm{CO}_{3}\right)$, biotin ((+)-biotin $\mathrm{N}$-hydroxysuccinimide ester), and streptavidin from bacterium Streptomyces avidinii were purchased from Sigma. Ammonium hydroxide $\left(\mathrm{NH}_{4} \mathrm{OH} 28 \%\right)$, poly(allylamine hydrochloride) $\left(M_{w} \sim 58,000\right.$, PAH), poly(sodium 4-styrenesulfonate) $\left(M_{w} \sim 70,000\right.$, PSS), and 3-aminopropyltrimethoxysilane (APTES) were purchased from Sigma-Aldrich. All reagents were of analytical grade and were used without further purification. Distilled water $(18.3 \mathrm{MOhm} \mathrm{cm})$ was obtained by reverse osmosis followed by ion exchange and filtration in Millipore-Q (Millipore, Direct-QTM).

The silica nanoparticles $\left(\mathrm{SiO}_{2} \mathrm{NPs}\right)$ were prepared following the Stober method [34]. A solution of gold nanoparticles (Au NPs) was prepared using the synthesis method described in [35]. The average nanoparticle diameters were $250 \mathrm{~nm}$ for $\mathrm{SiO}_{2}$ and $5 \mathrm{~nm}$ for $\mathrm{Au}$.

2.2. Sensors Fabrication and Coatings. Standard single mode optical fibres $(5 \mu \mathrm{m} / 125 \mu \mathrm{m}$ core/clad diameter, resp., Fibercore SM600) were tapered using an in-house system, heating the fibre using a $\mathrm{CO}_{2}$ laser and pulling using rotational stages. The lengths of the tapered regions were $1 \mathrm{~cm}$, with waist diameter of $14 \mu \mathrm{m}$ (Figure 1). The build system allows obtaining highly repeatable optical fibre tapered sensors. 


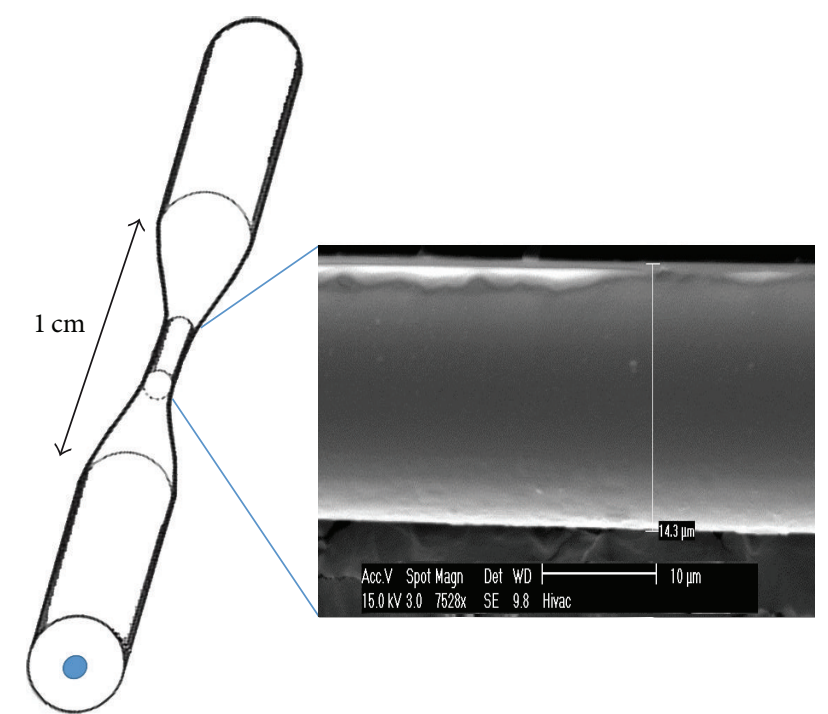

FIGURE 1: Scheme of the tapered optical fibres and SEM image of the tapered waist.

The tapered optical fibres were coated using two different methods, as described below.

2.2.1. Sputtering. The first taper (denoted as $\mathrm{T} 1_{\text {Au sputtered }}$, $14 \mu \mathrm{m}$ waist diameter and ca. $1 \mathrm{~cm}$ tapered region length) was coated with a gold thin film by sputtering [36] using the DC-sputter deposition process (Quorum Emitech K575x Sputter Coater, from Quorum Technologies) with a partial pressure of argon of $8 \times 10^{-2} \mathrm{mbar}$ and current of $70 \mathrm{~mA}$. The tapered optical fibre was fixed in a special holder to ensure that the taper was straight and taut and that allowed the deposition of $\mathrm{Au}$ on the entire surface of the tapered section of the optical fibre. No rotation mechanism was used in this case.

To determine the Au film thickness during the sputtering process, glass substrates were placed near the tapered optical fibre and coated simultaneously under the same conditions as optical fibre. The thickness was calculated by optical transmission measurements. The coating presented a uniform thin film of thickness ca. $10 \mathrm{~nm}$.

2.2.2. LbL Method. The second taper ( $\mathrm{T} 2_{\mathrm{Au} \mathrm{NPs}}$, waist diameter $14 \mu \mathrm{m}$ and $1 \mathrm{~cm}$ length) was modified using the LbL method as reported previously [31]. Briefly, the T2 tapered region was treated with a $10 \mathrm{mM} \mathrm{KOH}$ solution (ethanol: $\mathrm{H}_{2} \mathrm{O} 3: 2$ ) for 30 minutes to charge the region surface negatively. Then, it was immersed in a positively charged PAH solution for $25 \mathrm{~min}$ and cleaned with ultrapure water. After that, the fibre was introduced to a negatively charged $\mathrm{SiO}_{2}$ NPs solution for another $25 \mathrm{~min}$ and then cleaned with distilled water and flushed with $\mathrm{N}_{2}$ gas. The deposition process was repeated three times, facilitating the deposition of 3 (PAH: $\mathrm{SiO}_{2} \mathrm{NPs}$ ) bilayers onto the tapered area (see Figure 2).

Next, a layer of Au NPs was applied to the fibre to obtain $\mathrm{SiO}_{2}$ core $\mathrm{Au}$ shell nanoparticles, followed by two additional bilayers of PSS and Au NPs. Finally, the last immersion in the $\mathrm{Au}$ NPs solution was performed to obtain the $\mathrm{Au}$ as an outermost layer that would be used for biotin deposition.

Transmission spectra were captured after each step in the deposition of coatings on both T1 and T2. Once T1 and T2 were coated, they were ready for characterization and further binding of proteins.

2.3. Protein Binding Measurements. A $6.8 \mu \mathrm{M}$ aqueous solution of biotin $((+)$-biotin N-hydroxysuccinimide ester, from Sigma) and SV aqueous stock solutions ranging from $2.5 \mathrm{nM}$ to $1.33 \mu \mathrm{M}$ were prepared. After the modification procedure, the tapered optical fibres, $\mathrm{T} 1_{\text {Au sputtered }}$ and $\mathrm{T} 2_{\mathrm{AuNP}}$, were immersed in a $6.8 \mu \mathrm{M}$ biotin solution for $30 \mathrm{~min}$. The fibres were then rinsed with ultrapure water and dried under $\mathrm{N}_{2}$ gas stream. The $\mathrm{T} 1_{\text {Au sputtered }}$ and $\mathrm{T} 2{ }_{\text {Au NPs }}$ optical fibres were then exposed to streptavidin solutions for $20 \mathrm{~min}$ with concentrations ranging from $2.5 \mathrm{nM}$ to $1.33 \mu \mathrm{M}$, followed by washing in distilled water. Transmission spectra were recorded after the washing step in the solution.

2.4. Experimental Setup. The experimental setup used for testing the $\mathrm{T} 1_{\text {Ausputtered }}$ and $\mathrm{T} 2{ }_{\mathrm{AuNP}}$ devices is shown in Figure 3. A tungsten-halogen light source with a wavelength range of 350-2000 nm (HL-2000 from Ocean Optics) was connected to one of the optical fibre pigtails. The other pigtail was connected to a UV-VIS spectrometer (USB2000XR1 from Ocean Optics). The spectrometer has a wavelength range of 380 to $1000 \mathrm{~nm}$ and resolution of $0.5 \mathrm{~nm}$.

2.5. Film Morphology Characterisation. The morphology of the $\mathrm{PAH} / \mathrm{SiO}_{2}$ :Au films was studied using Philips XL 30 (SEM). The films deposited onto optical fibre were coated with a thin $(5 \mathrm{~nm})$ platinum film using a Quorum Technologies SC 7640 Auto/Manual Sputter Coater to allow electrical discharge of the sample surface during the interaction with the electron beam.

\section{Results and Discussion}

3.1. Optical Fibre Modification. As was commented previously, the tapered optical fibres were coated with Au thin films using 2 different approaches: (i) the sputtering technique and (ii) a novel facile method composed of layerby-layer deposition consisting of polycation (poly(allylamine hydrochloride), $\mathrm{PAH}$ ) and negatively charged $\mathrm{SiO}_{2}$ nanoparticles (NPs) followed by the deposition of the charged Au NPs.

In both approaches, in order to characterise the optical response of the mentioned devices, the original spectra before coating were measured at room conditions and with the device immersed into water (see Figures 4(a) and 4(b)). The maximum wavelength shift between the measurements in air and in water for $\mathrm{T} 1$ tapered fibre is ca. $10 \mathrm{~nm}$ in the range of 500-600 nm, whereas the shift for T2 tapered fibre is ca. $20 \mathrm{~nm}$ in the $700-900 \mathrm{~nm}$. This difference in sensitivities and the transmission spectra is due to slight 
(i) $\mathrm{KOH}$ treatment

(ii) $\mathrm{PAH}$

(iii) $\mathrm{SiO}_{2} \mathrm{NPs}$
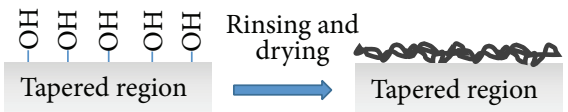

Rinsing and

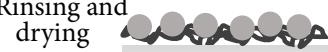

Tapered region

Tapered region

Tapered region

(v) PSS

(iv) Au NPs $:^{\circ}$

Repeat (ii) and (iii)

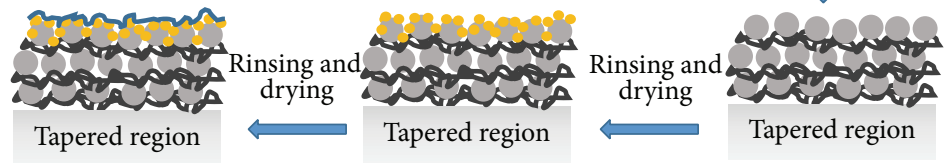

Repeat (iv) and (v)

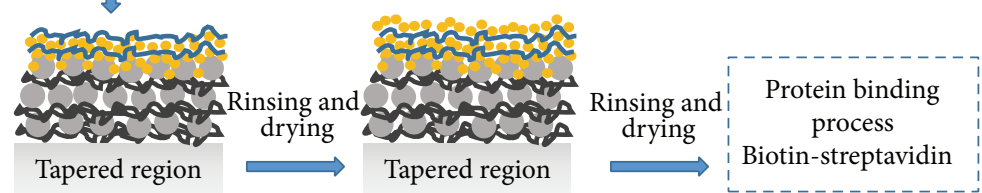

FIGURE 2: Schematic illustration of the coating process based on layer-by-layer method used to modify T2 device.

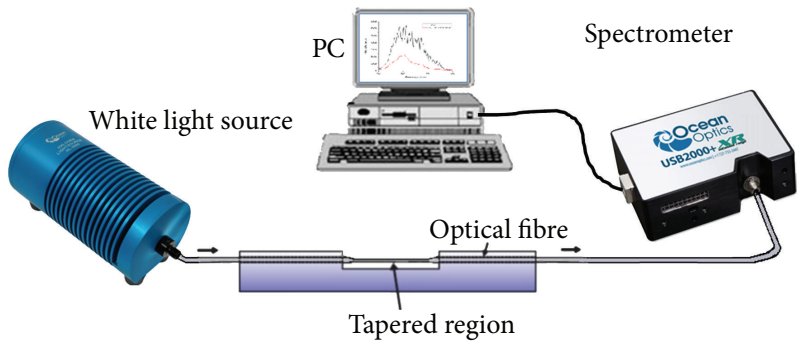

FIGURE 3: Experimental setup used to monitor the transmission spectra of the optical fibre sensors.

differences in geometry in the transition region of the tapers.

3.1.1. Sputtering Deposition ( $\left.T 1_{\text {Ausputtered }}\right)$. The original transmission spectrum of $\mathrm{T}_{1}$ Au sputtered was recorded along with the spectrum after the sputtering deposition of $\mathrm{Au}$. The $\mathrm{Au}$ deposition step results in a significant attenuation of the transmitted signal. The characteristic fringes of the nonadiabatic taper are no longer visible after sputtering the $\mathrm{Au}$ thin film (shown in Figure 4(a)). The broad decrease in transmission in the $550 \mathrm{~nm}-700 \mathrm{~nm}$ region is believed to be a result of a plasmon peak of the $\mathrm{Au}$ film. These results correspond well to the previously published data $[37,38]$.

The disappearance of the characteristic interference fringes is most plausibly a result of the high imaginary part of the RI of the Au coating, which suppresses the excitation of the higher order modes in the tapered region of the optical fibre.

3.1.2. LbL Deposition ( $T 2_{A u N P s}$ ). Similarly, the transmission spectrum of the $\mathrm{T} 22_{\mathrm{AuNPs}}$ sensor was recorded during the
LbL film deposition process. The initial LbL steps cause a red wavelength shift due to the deposition of the $\mathrm{PAH} / \mathrm{SiO}_{2}$ NPs bilayers, which is typical behaviour observed during the deposition of thin films onto tapered optical fibres [39]. Similar behaviour was observed during the deposition of the Au NPs (Figure 4(b)). The amplitude of the change, however, was larger, most likely a result of the higher RI of the Au NPs. Following the further Au NPs adhesion, important signal losses and wavelength shifts in some spectral regions are observed. In contrast to the sputtering process, not all of the oscillation features disappeared after deposition of the Au NPs (Figure 4(b)) and some intensity peaks remained, which were taken into account as a reference for sensing mechanism. Figure 4(b) shows noticeable variations in the $750 \mathrm{~nm}-$ $900 \mathrm{~nm}$ region at the sensor surface functionalization with $\mathrm{Au}$ NPs.

The difference between the sputtering and LbL deposition of the Au film could be related to the difference in structure of the deposited film. In the case of the sputtering, the highly uniform film can be obtained [37, 38], while the attachment of the $\mathrm{Au}$ NPs to the $\mathrm{SiO}_{2}$ mesoporous thin film results in the film structure that does not suppress the coupling of the higher order modes and thus retains the fringes in the transmission spectrum. The further work is required to understand this difference in more detail. It should be noted that difference in bulk refractive index sensitivities of the unmodified $\mathrm{T} 1$ and $\mathrm{T} 2$ sensors cannot account for such a drastic difference in the response to the $\mathrm{Au}$ film deposition.

3.1.3. SEM Surface Morphology. Figures 5(a) and 5(b) show SEM images of the optical fibre surface morphology after the deposition of the Au films using the sputtering and LbL methods and after SV measurements, respectively. The surface was uniformly covered after both the sputtering and LbL methods but had protein attached to it after the SV 


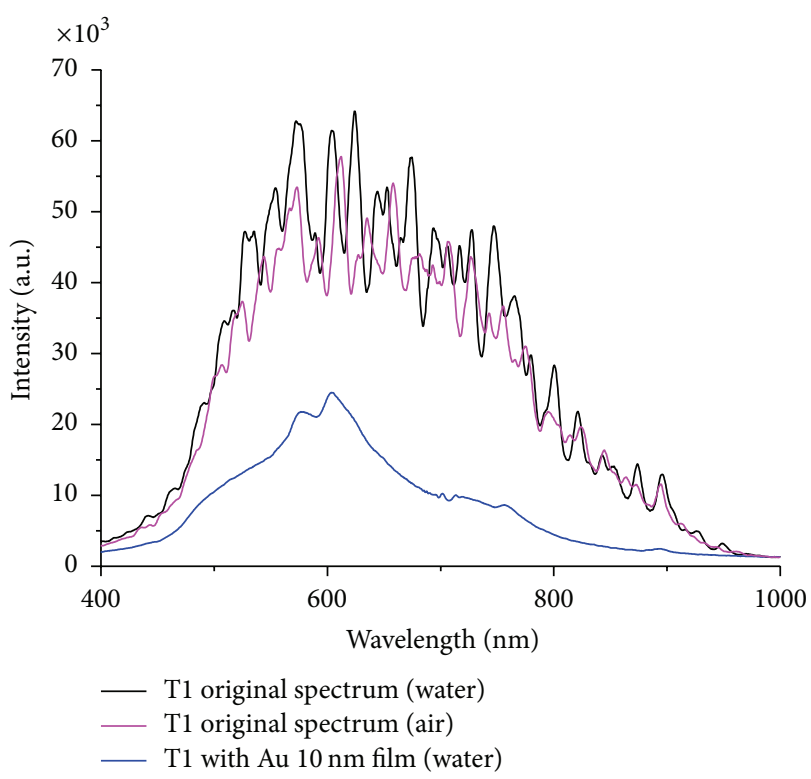

(a)

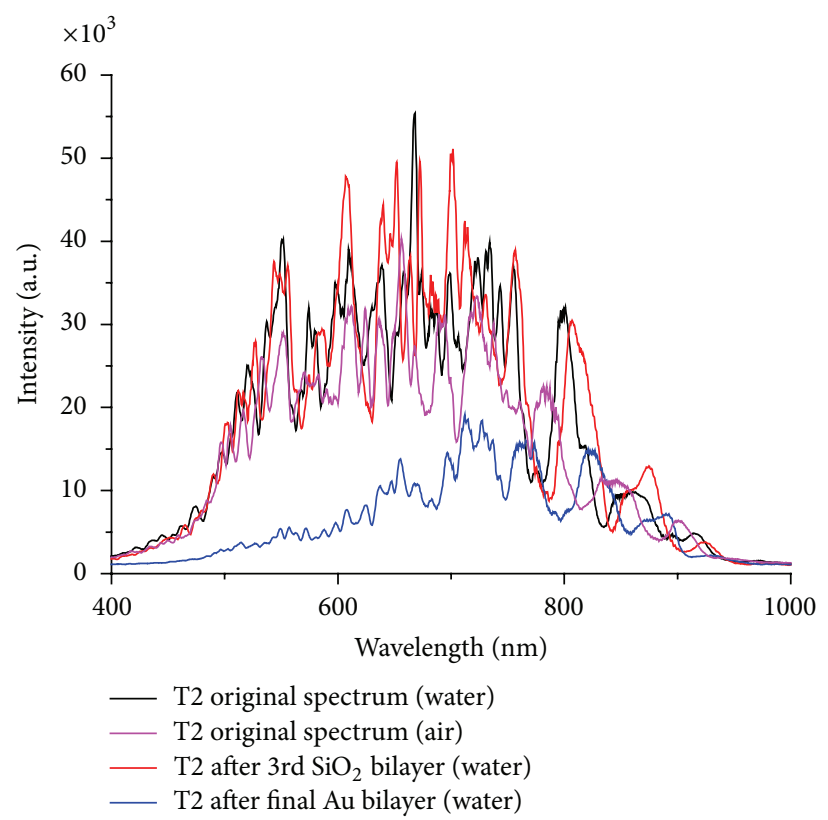

(b)

FIGURE 4: Transmission spectra of (a) $\mathrm{T} 1_{\text {Au sputtered }}$ and (b) $\mathrm{T} 2_{\mathrm{Au} \mathrm{NPs}}$ measured before modification: black line, in water, magenta line, in air, red line, after deposition of the $\mathrm{SiO}_{2}$ thin film, and blue line, after deposition of the Au thin film.

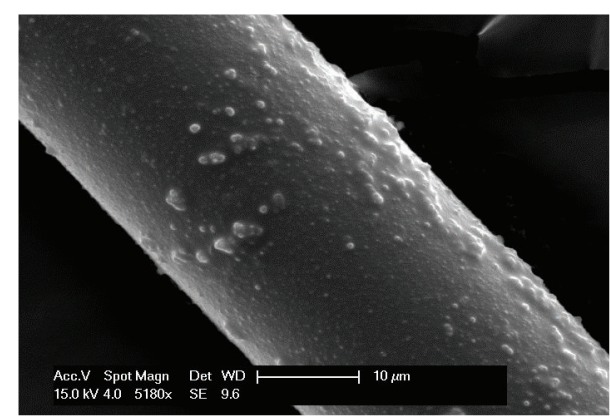

(a)

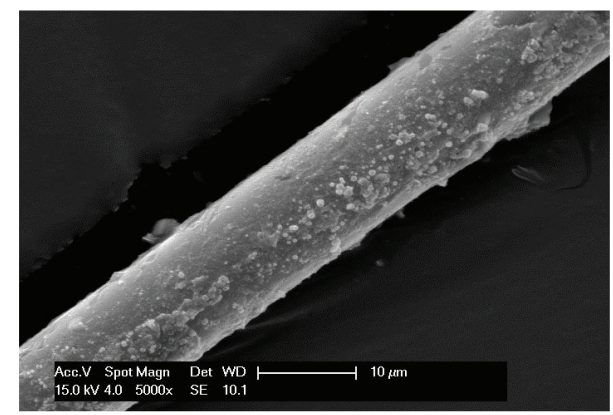

(b)

FIGURE 5: SEM image of the optical fibre surface morphology after the deposition of the Au films using (a) sputtering and (b) LbL methods.

adsorption, corresponding to the bright spots in SEM images. The agglomeration of proteins leads to a rougher surface. In addition, the platinum thin film deposited to prepare the SEM sample (see Section 2.5) contributed to higher roughness. It should be noted that Figure 5(a) was measured slightly outside of the tapered region and therefore diameter of the optical fibre is larger than $14 \mu \mathrm{m}$.

It should be noted that this deposition method provides much better surface coverage of the optical fibre in comparison to the previously used one [40], where $\mathrm{SiO}_{2}$ were first modified with $\mathrm{Au}$ NPs and then deposited onto long period grating optical fibre sensor. The two-stage deposition method proposed in this paper allows for better surface coverage and, as will be shown later, higher sensitivity to SV. The typical surface roughness of the Au film after sputtering is $0.3-0.8 \mathrm{~nm}$ [41].
3.2. Sensing Principle for the Protein Binding. The sensing principle for both $\mathrm{T} 1$ and $\mathrm{T} 2$ is based on the evanescent field theory [42]. Tapered optical fibres present characteristic losses in the transmission spectra due to the coupling of the fundamental core mode to the higher order modes in the 1st tapered region. These higher order modes leak partially into the surrounding medium and consequently interfere on recombination with the fundamental mode at the 2 nd taper region. A change in the RI of the surrounding medium leads to a modification of the coupling conditions and is accompanied by a modification of the transmission spectrum of the tapered optical fibre sensors. Typically, the changes in both wavelength position of the interference fringes and intensity losses are observed [39]. In general nonadiabatic tapers are used because their abrupt transitions generate a number of modes in the tapered region, and the interference between 


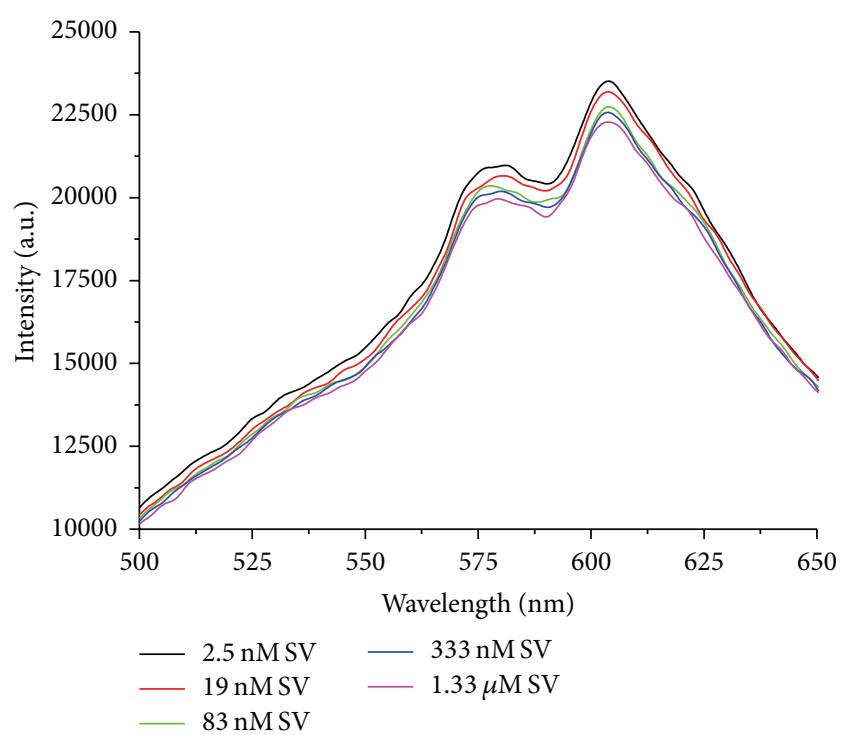

(a)

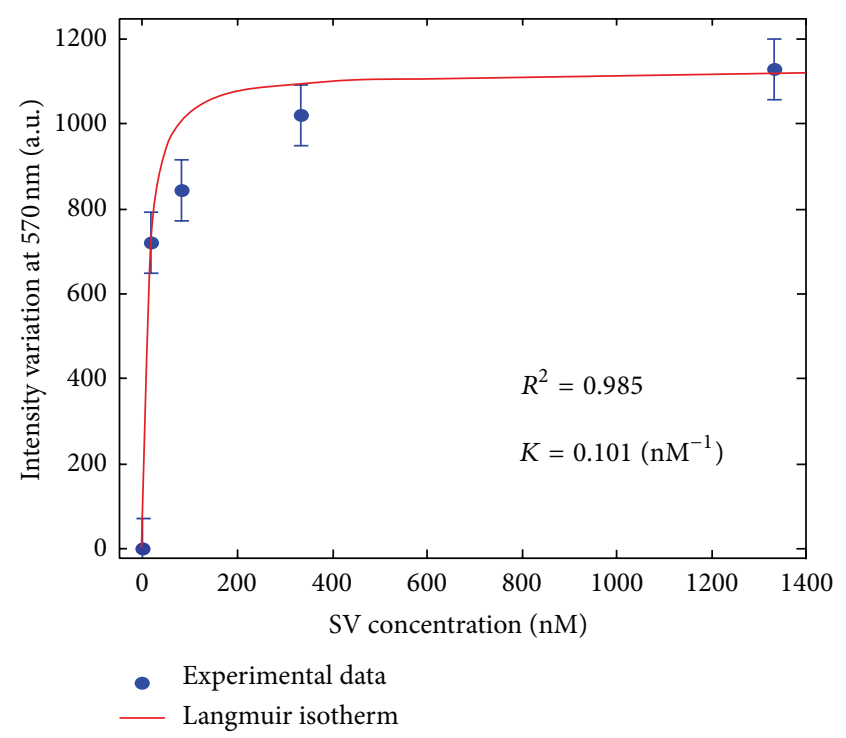

(b)

FIGURE 6: (a) Transmission spectra variations at different SV concentrations in the wavelength range of 500-650 nm; (b) intensity peak variations for each SV concentration and corresponding Langmuir isotherm fit $\left(\mathrm{T} 1_{\text {Au sputtered }}\right.$ device $)$.

these modes creates characteristic fringes in the transmission spectrum. Monitoring both the intensity and wavelength of the fringes could offer better intrinsic properties in terms of sensitivity. Here it was found that these fringes disappeared after deposition of the coating, but it was still possible to monitor analyte induced changes in the transmitted intensity. Once the tapered regions are coated with the appropriate capture layer, they can act as sensitive regions for the analyte of interest.

The biotin-streptavidin binding process is well known from the literature $[35,43]$. The binding of SV to the biotin coated fibre produces a detectable change in the measured refractive index (RI). The increase of external RI when streptavidin binds to biotin intensifies the optical transmission losses. According to the evanescent field theory [41], when the external media RI is higher than core RI, if the difference between the external RI and the core RI increases, then the optical losses also grow along with the wavelengths shift of the interference features $[44,45]$. The number of SV molecules that bind to the biotin is dependent on the concentration of SV. Based on this binding dependence and the sensing principle, it is possible to detect changing SV concentrations in the intensity function of the wavelength spectra. This behaviour in the $550-900 \mathrm{~nm}$ range was monitored and represented for $\mathrm{T} 1_{\text {Au sputtered }}$ and $\mathrm{T} 22_{\mathrm{AuNPs}}$ in a wide range of concentrations from $2.5 \mathrm{nM}$ to $1.33 \mu \mathrm{M}$.

3.2.1. Sputtering-Based Sensor ( $\left.T 1_{\text {Ausputtered }}\right)$. According to the sensing principle discussed previously, optical signal levels change over a wide range of wavelengths with the increase of SV concentration. Signal losses in the spectra are observed to higher binding levels of SV. The transmission spectra of $\mathrm{T} 1_{\text {Au sputtered }}$ after $\mathrm{SV}$ treatment are shown in
Figures 6 and S1, in Supplementary Material available online at http://dx.doi.org/10.1155/2016/8129387.

The sputtered Au thin film contributes to a decrement in intensity in the $550 \mathrm{~nm}-700 \mathrm{~nm}$ range because of the surface plasmon resonance (SPR) phenomenon. The presence of the $\mathrm{Au}$ SPR band provides more signal losses in this wavelength range (see Figure 6(a)). During the SV-biotin binding, a decrease in intensity is observed. The spectra behaviour can be described as follows. At lower SV concentrations, the transmission spectra present more changes in magnitude due to the higher amount of free biotin molecules to bind with SV. Further, by increasing the SV concentration in solution, the amount of free biotin decreases until a saturation threshold is reached. This behaviour is reported in more detail in Section 3.3.

3.2.2. LbL-Based Sensor $\left(T 2_{A u N P s}\right)$. For $\mathrm{T} 22_{\mathrm{AuNPs}}$ sensor, a higher level of optical losses with increasing SV concentration was also observed. The $\mathrm{T} 2 \mathrm{AuNP}_{\mathrm{As}}$ intensity variation is more influenced by the SV concentration, as compared to the results from $\mathrm{T} 1_{\text {Au sputtered }}$ sensor. The transmission spectrum was monitored for SV concentrations ranging from $2.5 \mathrm{nM}$ to $1.33 \mu \mathrm{M}$ (Figures 7 and S2).

A decrease in the signal intensity is observed with the increase in SV concentration. These experimental results can also be analysed by measuring the wavelength shifts of the interference features in the transmission spectra, where the intensity peak at ca. $825 \mathrm{~nm}$ showed a shift of $7.8 \mathrm{~nm}$ on exposure to $1.33 \mu \mathrm{M}$ SV concentration, Figure 8 (a). The binding process between biotin and SV takes place with the biotin molecules coated over the fibre and the addition of SV molecules in solution. Plotting together the protein binding data and respective intensity values, an inverted 


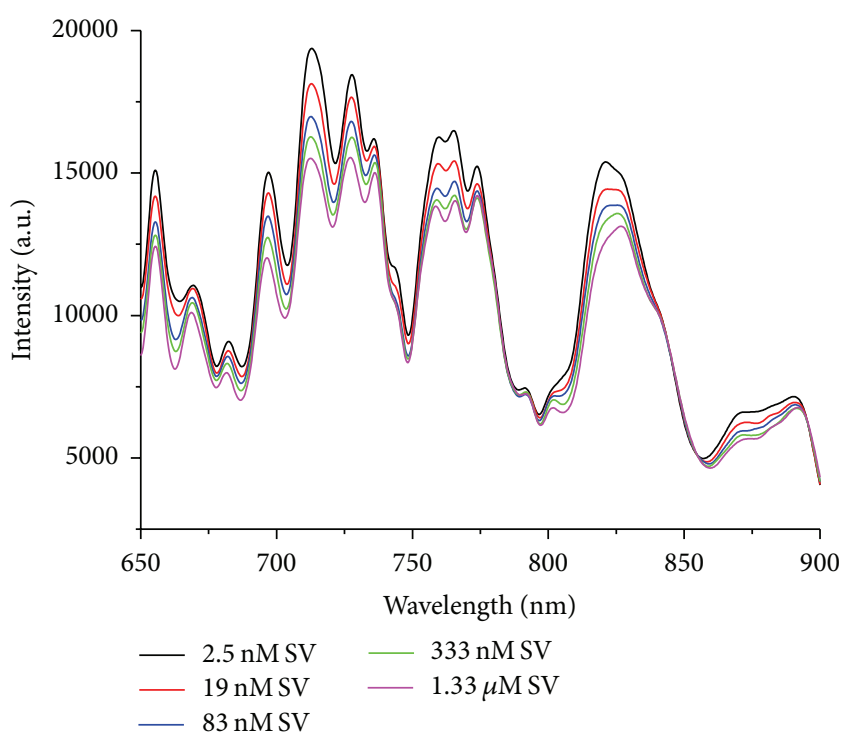

Figure 7: Transmission spectra variations measured using the $\mathrm{T} 2_{\mathrm{Au} \mathrm{NPs}}$ device at different SV concentrations.

relationship is observed. The $\mathrm{T} 2$ Au NPs sensor can detect SV concentrations by two methods: by wavelength shifts and intensity changes.

The wavelength shift as a function of SV concentration follows the Langmuir binding model [46, 47]. According to the Langmuir isotherm equation, the equilibrium binding constant $(K)$ was determined as described in [46]. The obtained $K$ value was $2.2 \times 10^{-11} \mathrm{M}^{-1}$ and the Langmuir isotherm plot shows the good fitting of the experimental results in Figure 9(a). Moreover, the intensity change follows the same binding model with a binding constant $K$ of $4.5 \times$ $10^{-11} \mathrm{M}^{-1}$ (see Figure 9(b)).

It should be noted that the sensitivity is higher when intensity is measured as compared to that achieved using the wavelength shift detection method, which consequently leads to the larger binding constant, Figures 9(a) and 9(b) (Figures S3-S5).

3.3. $T 1_{\text {Ausputtered }}$ and $T 2_{A u N P s}$ Comparison. From the previous measurements taken using $\mathrm{T} 1_{\text {Au sputtered }}$ and $\mathrm{T} 22_{\mathrm{AuNPs}}$ devices, the intensity peaks were analysed to calculate the transfer function.

The intensity peak values at $575 \mathrm{~nm}$ (Figure S1) for $\mathrm{T} 1_{\text {Au sputtered }}$ are represented in Figure 10 . Three intensity peak values for $\mathrm{T} 22_{\mathrm{AuNP}}$ in the $700-900 \mathrm{~nm}$ region (at ca. 715,765 , and $825 \mathrm{~nm}$ ) as function of the SV concentration are also shown. These plots represent the logarithmic behaviour of the spectral features of the $\mathrm{T} 1_{\text {Au sputtered }}$ and $\mathrm{T} 2{ }_{\mathrm{AuNPs}}$ devices during the biotin-SV binding process in terms of intensity. They can be fitted and considered as sensor transfer functions or calibration plots. It is important to remark that they cover a wide dynamic range of SV concentration but also exhibit a very high sensitivity mainly for the lowest concentrations (from $2.5 \mathrm{nM}$ to $19 \mathrm{nM}$ range in both devices). It should be noted that two sensors have highest sensitivity in different spectral range. This is expected because of the effect of the difference in the film structure and its effect on the optical properties of the tapered sensors, Figure 4.

According to these results, $\mathrm{T} 1_{\text {Au sputtered }}$ and $\mathrm{T} 2{ }_{\mathrm{Au} \mathrm{NPs}}$ show variations in intensity for all SV concentrations ranges, thus offering protein detection of at least $2.5 \mathrm{nM}$. The limits of detection of SV were calculated to be the concentration which yielded a signal 3 times the average noise level (32.82 a.u.) [48]. These LoD were $8.06 \times 10^{-10} \mathrm{M}$ and $2.71 \times 10^{-10} \mathrm{M}$ for $\mathrm{T} 1_{\text {Au sputtered }}$ and $\mathrm{T} 22_{\mathrm{AuNPs}}$, respectively (data shown in Figures S6 and S7), revealing that sensor modified with the $\mathrm{SiO}_{2}$ :Au NPs has ca. 3 times lower LoD that sensor prepared using sputtering. It should be noted that both values are similar to or better than other optical fibre devices $[7,49-51]$.

The $\mathrm{T} 2{ }_{\mathrm{AuNP}}$ device has greater sensitivity and can detect SV concentration changes by using three different wavelengths peaks. Moreover, T2 ${ }_{\text {Au NPs }}$ can also detect SV variations by monitoring the wavelength change thus allowing additional wavelength-based sensing measurements. The higher sensitivity of the $715 \mathrm{~nm}$ peak is most plausible owing to the closer location to the SPR peak as compared with peaks at longer wavelength.

The source of the difference between the $\mathrm{T} 1_{\text {Au sputtered }}$ and $\mathrm{T} 22_{\mathrm{Au} \mathrm{NPs}}$ devices is located in their sensitive regions and their nanostructured morphology. In fact, the key factor is the SV absorption capacity in these coatings. On one hand, the LbL coating morphology with the Au NPs provides a higher specific surface area for the adhesion of more biotin molecules. In addition, $\mathrm{T} 2$ Au NPs presents higher sensitivity in the region around $750-800 \mathrm{~nm}$ related to the localized surface plasmon resonance due to the presence of the $\mathrm{Au} \mathrm{NPs}_{-} \mathrm{SiO}_{2}$ NPs combination, as it is reported in $[52,53]$. According to this, $\mathrm{T} 2 \mathrm{AuNPs}_{\mathrm{A}}$ presents higher threshold saturation and higher dynamic range. On the other hand, $\mathrm{T} 1_{\text {Ausputtered }}$ provides less surface area to allocate the biotin molecules because of its uniform $\mathrm{Au}$ monolayer, and therefore it has less sensitivity than $\mathrm{T} 2 \mathrm{AuNPs}_{\mathrm{A}}$. However, as it was reported previously, both devices present relevant LoD values (806 pM from $\mathrm{T} 1_{\text {Au sputtered }}$ and $271 \mathrm{pM}$ from $\left.\mathrm{T} 2 \mathrm{AuNPs}_{\mathrm{N}}\right)$. Although, as mentioned in Section 3.1, the sensitivities to the bulk refractive index of the devices $\mathrm{T} 1$ and $\mathrm{T} 2$ before modification were different, this cannot account for the factor of 3 times difference in the LoD of SV between $\mathrm{T} 1_{\text {Au sputtered }}$ and T2 $2_{\text {Au NPs }}$.

\section{Conclusions}

In this paper, two novel protein sensors based on tapered optical fibres are reported, analysed, and compared. The sensors $\left(\mathrm{T} 1_{\text {Au sputtered }}\right.$ and $\left.\mathrm{T} 2_{\text {Au NPs }}\right)$ were coated on the tapered regions with nanostructured $\mathrm{Au}$-based coatings. In case of the $\mathrm{T} 1_{\text {Au sputtered }}$ sensor, the taper was coated with a $10 \mathrm{~nm}$ Au thin film using a sputtering technique. For $\mathrm{T} 2 \mathrm{Au} \mathrm{NPs}_{\mathrm{A}}$, three bilayers of PAH:SiO ${ }_{2}$ NPs, followed by 2 bilayers of Au NPs:PSS and a final layer of $\mathrm{Au}$ NPs, were deposited onto the taper by the layer-by-layer method. 


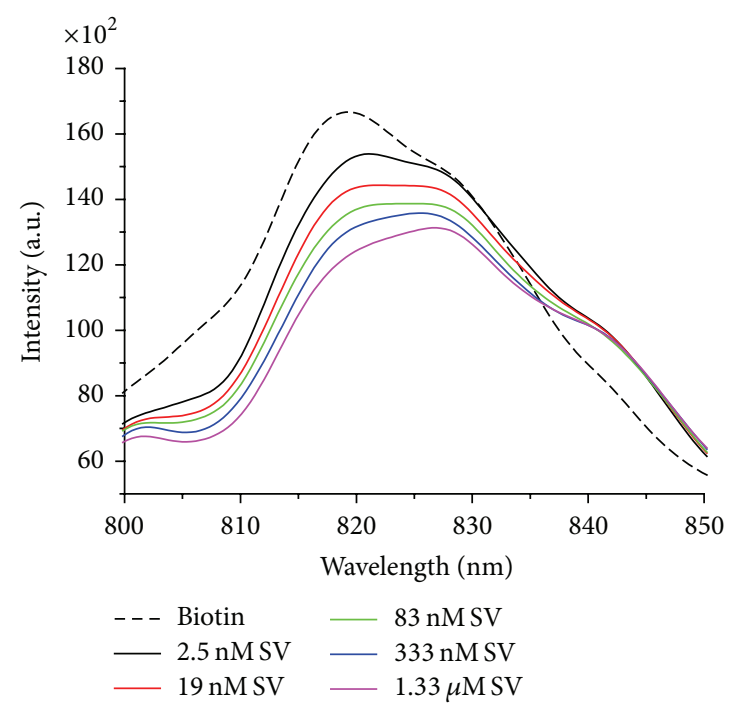

(a)

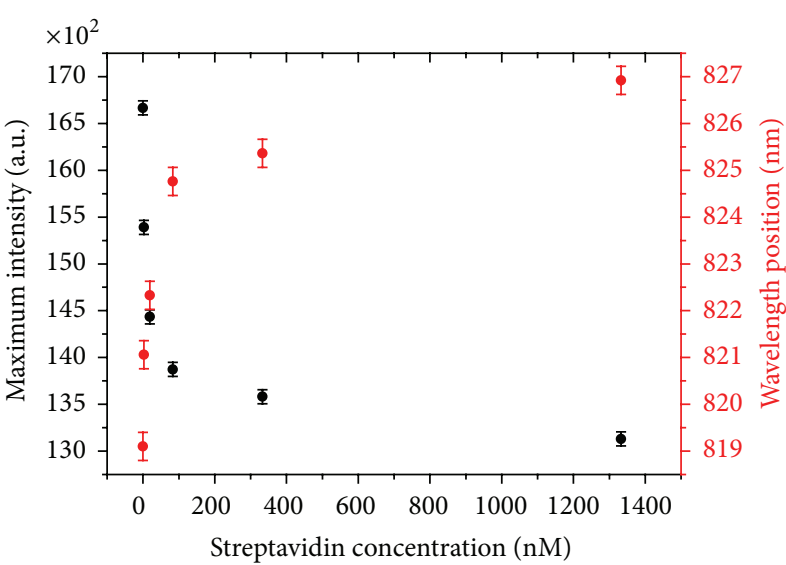

- Maximum intensity (a.u.)

- Wavelength position (nm)

(b)

FIgURE 8: (a) Detail of the transmission spectra in the wavelength region where the shift is observed (T2 ${ }_{\text {Au NPs }}$ device); (b) signal maxima intensities (black squares) and their respective wavelength position values (red squares) for each SV concentration (T2 ${ }_{\text {Au NPs }}$ device). The error bars represent the standard deviation of blank measurements and wavelength shifts are taking into account resolution of the spectrometer $\pm 0.25 \mathrm{~nm}$ and \pm 70 counts for intensity measurements.

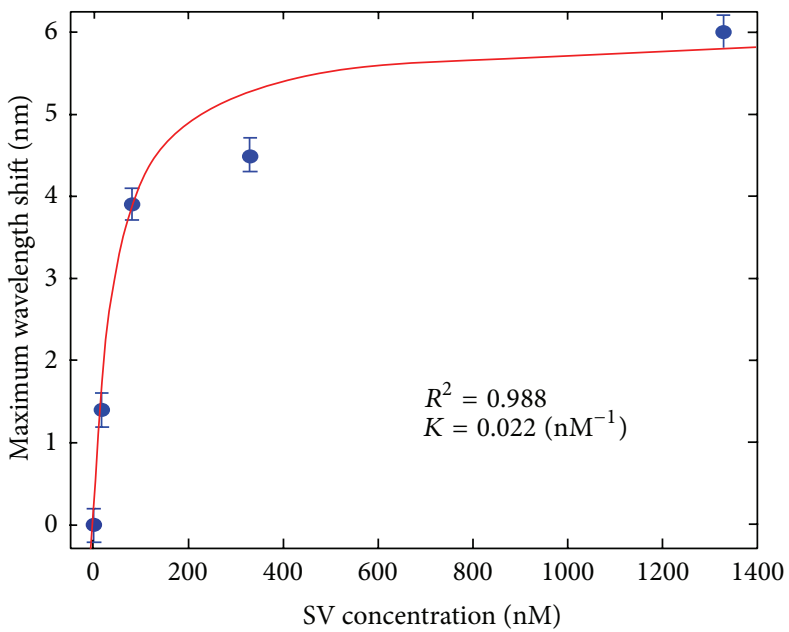

- Experimental data

— Langmuir isotherm

(a)

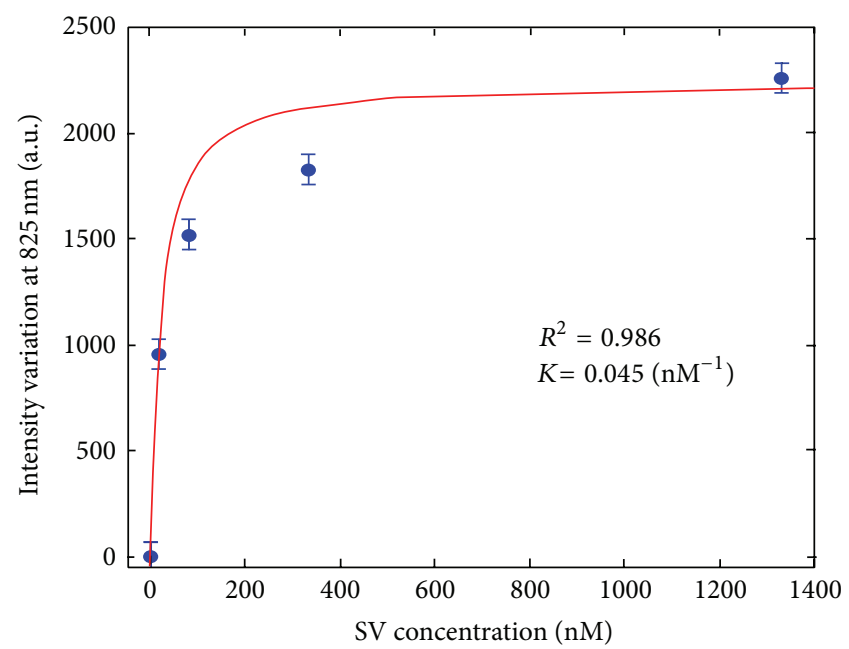

- Experimental data

_ Langmuir isotherm

(b)

FIgURE 9: (a) Absolute wavelength shift values and (b) intensity peak variations for each SV concentration and corresponding Langmuir isotherm for $\mathrm{T} 2 \mathrm{Au} \mathrm{NPs}_{\mathrm{s}}$ device. The error bars represent the standard deviation of blank measurements and wavelength shifts are taking into account resolution of the spectrometer $\pm 0.25 \mathrm{~nm}$ and \pm 70 counts for intensity measurements.

Both the $\mathrm{T} 1_{\text {Au sputtered }}$ and $\mathrm{T} 22_{\text {Au NPs }}$ sensors were coated with biotin to provide binding sites for SV molecules. BiotinSV binding was detected by monitoring optical losses in the transmission spectra of the tapered optical fibre. The sensing principle of the devices is explained using evanescent field theory. The higher concentration of SV bound to biotin produces additional signal losses, due to sensing layer RI changes. When the external RI is higher than the core RI, as the differences between the sensing layer RI and the core RI increase, the optical losses increase.

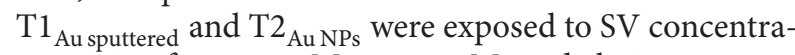
tions ranging from $2.5 \mathrm{nM}$ to $1.33 \mu \mathrm{M}$, and their responses were monitored and analysed. $\mathrm{T} 1_{\text {Au sputtered }}$ and $\mathrm{T} 2_{\mathrm{AuNPs}}$ presented a logarithmic response (optical signal versus SV 


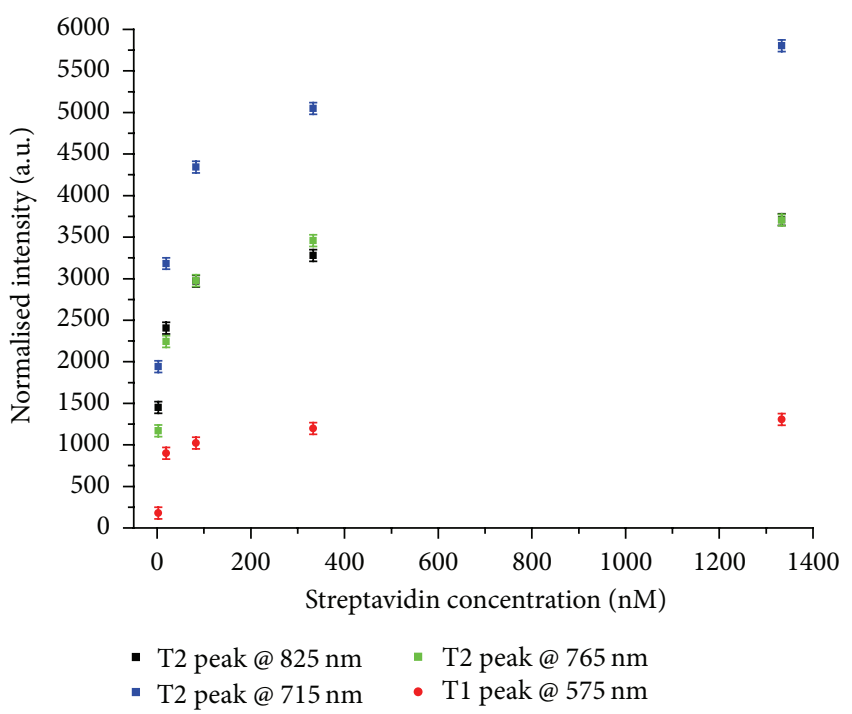

FIgURE 10: $\mathrm{T} 1_{\text {Au sputtered }}$ and $\mathrm{T} 2{ }_{\mathrm{AuNPs}}$ transfer functions: intensity maximum peaks for the different SV concentrations normalised with respect to the spectra peaks captured after biotin adhesion (null SV concentration). Error bars represent the standard deviation of blank measurements ( \pm 70 counts for intensity measurements).

concentration) as expected given the known SV-biotin binding reaction. Both $\mathrm{T} 1_{\mathrm{Au} \text { sputtered }}$ and $\mathrm{T} 2_{\mathrm{Au} \mathrm{NPS}}$ sensors could detect levels of SV below $2.5 \mathrm{nM}$. T2 2 Au NPs provided enhanced results in terms of sensitivity and dynamic range, and it could also detect the SV variations from 3 simultaneous peaks measurements, also using wavelength shift-based measurements. LbL coatings based on Au NPs have a higher surface area than do sputtered $\mathrm{Au}$ thin films, and so they are more efficient in the biotin adhesion process and therefore in SV concentration detection.

Future work could focus on improving and optimizing the sensor design to get a lower LoD and improved properties in terms of selectivity, dynamic range, and sensor response time. In this work the binding time allowed was $20 \mathrm{~min}$, taken from previously published work [5].

The development of these coated sensors demonstrates that the concept of tapered optical fibres and their configurations is capable of detecting not only proteins but also other substances such as volatile organic compounds, gases, and relative humidity, with ultra-low LoD values.

\section{Data Access}

For enquiries relating to access to the research data or other materials referred to in this paper, please contact Cranfield University Library and Information Services, library@cranfield.ac.uk.

\section{Competing Interests}

The authors state that there are not any competing interests.

\section{Acknowledgments}

This work was supported in part by the Spanish Ministry of Economy and Competitiveness-CICYT-FEDER TEC201343679R Research Grant and UPNA predoctoral and mobility research grants. The authors also acknowledge the support of UK Engineering and Physical Sciences Research Council Platform grant (EP/H02252X/1) and responsive mode grant (EP/L010437/1). The authors would like also to acknowledge the support of the EPSRC EP/G061661/1 Advanced Ultrasonics Platform Grant, University of Nottingham, Dean of Engineering Faculty Award.

\section{References}

[1] F. Bănică, Chemical Sensors and Biosensors: Fundamentals and Applications, John Wiley \& Sons, Chichester, UK, 2012.

[2] B. Culshaw and A. Kersey, "Fiber-optic sensing: a historical perspective," Journal of Lightwave Technology, vol. 26, no. 9, pp. 1064-1078, 2008.

[3] J. R. Casas and P. J. S. Cruz, "Fiber optic sensors for bridge monitoring," Journal of Bridge Engineering, vol. 8, no. 6, pp. 362-373, 2003.

[4] B. Lee, "Review of the present status of optical fiber sensors," Optical Fiber Technology, vol. 9, no. 2, pp. 57-79, 2003.

[5] L. Marques, F. U. Hernandez, S. Korposh et al., "Sensitive protein detection using an optical fibre long period grating sensor anchored with silica core gold shell nanoparticles," in 23rd International Conference on Optical Fibre Sensors, vol. 9157 of Proceedings of SPIE, The International Society for Optical Engineering, June 2014.

[6] P. Pilla, A. Sandomenico, V. Malachovská et al., "A protein-based biointerfacing route toward label-free immunoassays with long period gratings in transition mode," Biosensors and Bioelectronics, vol. 31, no. 1, pp. 486-491, 2012.

[7] S. Lepinay, A. Staff, A. Ianoul, and J. Albert, "Improved detection limits of protein optical fiber biosensors coated with gold nanoparticles," Biosensors and Bioelectronics, vol. 52, pp. 337344, 2014.

[8] M. P. DeLisa, Z. Zhang, M. Shiloach et al., "Evanescent wave long-period fiber bragg grating as an immobilized antibody biosensor," Analytical Chemistry, vol. 72, no. 13, pp. 2895-2900, 2000.

[9] D. J. J. Hu, J. L. Lim, M. K. Park et al., "Photonic crystal fiberbased interferometric biosensor for streptavidin and biotin detection," IEEE Journal on Selected Topics in Quantum Electronics, vol. 18, no. 4, pp. 1293-1297, 2012.

[10] S. L. Zhu, J. B. Zhang, L. Y. L. Yue, D. Hartono, and A. Q. Liu, "Label-free protein detection via gold nanoparticles and localized surface plasmon resonance," Advanced Materials Research, vol. 74, pp. 95-98, 2009.

[11] H. T. Beier, G. L. Coté, and K. E. Meissner, "Whispering-gallerymode-based biosensing using quantum dot-embedded microspheres," in Colloidal Quantum Dots for Biomedical Applications $V$, vol. 7575 of Proceedings of SPIE, February 2010.

[12] L. K. Chin, C. S. Lim, and A. Q. Liu, "On-chip multiphase tunable grating interferometer for chemical and protein analysis," in Proceedings of the IEEE PhotonicsGlobal at Singapore (IPGC '08), pp. 1-3, Singapore, December 2008.

[13] S. O. Korposh, Y. P. Sharkan, M. Y. Sichka, D.-H. Yang, S.-W. Lee, and J. J. Ramsden, "Matrix influence on the optical response of 
composite bacteriorhodopsin films to ammonia," Sensors and Actuators B: Chemical, vol. 133, no. 1, pp. 281-290, 2008.

[14] K. T. V. Grattan and B. T. Meggitt, Optical Fiber Sensor Technology, Vol. 4: Chemical and Environment Sensing, Kluwer Academic, Dordrecht, Netherlands, 1999.

[15] O. S. Wolfbeis, "Fiber-optic chemical sensors and biosensors," Analytical Chemistry, vol. 76, no. 12, pp. 3269-3284, 2004.

[16] R. Bogdanowicz, M. Sobaszek, J. Ryl et al., "Improved surface coverage of an optical fibre with nanocrystalline diamond by the application of dip-coating seeding," Diamond and Related Materials, vol. 55, pp. 52-63, 2015.

[17] J. Goicoechea, C. R. Zamarreño, I. R. Matías, and F. J. Arregui, "Optical fiber $\mathrm{pH}$ sensors based on layer-by-layer electrostatic self-assembled Neutral Red," Sensors and Actuators, B: Chemical, vol. 132, no. 1, pp. 305-311, 2008.

[18] M. Partridge, R. Wong, S. W. James, F. Davis, S. P. J. Higson, and R. P. Tatam, "Long period grating based toluene sensor for use with water contamination," Sensors and Actuators B: Chemical, vol. 203, pp. 621-625, 2014.

[19] N. Cennamo, D. Massarotti, L. Conte, and L. Zeni, "Low cost sensors based on SPR in a plastic optical fiber forbiosensor implementation," Sensors, vol. 11, no. 12, pp. 11752-11760, 2011.

[20] A. Leung, P. M. Shankar, and R. Mutharasan, "A review of fiberoptic biosensors," Sensors and Actuators B: Chemical, vol. 125, no. 2, pp. 688-703, 2007.

[21] D. J. Monk and D. R. Walt, "Optical fiber-based biosensors," Analytical and Bioanalytical Chemistry, vol. 379, no. 7-8, pp. 931945, 2004.

[22] B. D. Gupta and R. K. Verma, "Surface plasmon resonancebased fiber optic sensors: principle, probe designs, and some applications," Journal of Sensors, vol. 2009, Article ID 979761, 12 pages, 2009.

[23] Z. Chen, Z. Dai, N. Chen et al., "Gold nanoparticles-modified tapered fiber nanoprobe for remote SERS detection," IEEE Photonics Technology Letters, vol. 26, no. 8, pp. 777-780, 2014.

[24] Q. Zhang, C. Xue, Y. Yuan, J. Lee, D. Sun, and J. Xiong, "Fiber surface modification technology for Fiber-Optic localized surface plasmon resonance biosensors," Sensors, vol. 12, no. 3, pp. 2729-2741, 2012.

[25] S. K. Srivastava and B. D. Gupta, "A multitapered fiber-optic SPR sensor with enhanced sensitivity," IEEE Photonics Technology Letters, vol. 23, no. 13, pp. 923-925, 2011.

[26] J. Villatoro, D. Monzón-Hernández, and E. Mejía, “Fabrication and modeling of uniform-waist single-mode tapered optical fiber sensors," Applied Optics, vol. 42, no. 13, pp. 2278-2283, 2003.

[27] Ó. Esteban, A. González-Cano, N. Díaz-Herrera, and M.-C. Navarrete, "Absorption as a selective mechanism in surface plasmon resonance fiber optic sensors," Optics Letters, vol. 31, no. 21, pp. 3089-3091, 2006.

[28] Rajan, S. Chand, and B. D. Gupta, "Surface plasmon resonance based fiber-optic sensor for the detection of pesticide," Sensors and Actuators B: Chemical, vol. 123, no. 2, pp. 661-666, 2007.

[29] L. Tang, Y. Ren, B. Hong, and K. A. Kang, "Fluorophore-mediated, fiber-optic, multi-analyte, immunosensing system for rapid diagnosis and prognosis of cardiovascular diseases," Journal of Biomedical Optics, vol. 11, no. 2, Article ID 021011, 2006.

[30] G. Decher, "Fuzzy nanoassemblies: toward layered polymeric multicomposites," Science, vol. 277, no. 5330, pp. 1232-1237, 1997.

[31] K. Ariga, J. P. Hill, and Q. Ji, "Layer-by-layer assembly as a versatile bottom-up nanofabrication technique for exploratory research and realistic application," Physical Chemistry Chemical Physics, vol. 9, no. 19, pp. 2319-2340, 2007.

[32] N. M. Green, "Avidin," Advances in Protein Chemistry, vol. 29, pp. 85-133, 1975.

[33] K. Misiakos, S. E. Kakabakos, P. S. Petrou, and H. H. Ruf, "A monolithic silicon optoelectronic transducer as a real-time affinity biosensor," Analytical Chemistry, vol. 76, no. 5, pp. 13661373, 2004.

[34] W. Stöber, A. Fink, and E. Bohn, "Controlled growth of monodisperse silica spheres in the micron size range," Journal of Colloid and Interface Science, vol. 26, no. 1, pp. 62-69, 1968.

[35] C. Bonnard, D. S. Papermaster, and J. P. Kraehenbuhl, “The streptavidin-biotin bridge technique: application in light and electron microscope immunocytochemistry," Immunolabelling for Electron Microscopy, pp. 95-111, 1984.

[36] P. Sigmund, "Elements of sputtering theory," in Nanofabrication by Ion-Beam Sputtering: Fundamentals and Applications, pp. 140, CRC Press, 2012.

[37] D. Gaspar, A. C. Pimentel, T. Mateus et al., "Influence of the layer thickness in plasmonic gold nanoparticles produced by thermal evaporation," Scientific Reports, vol. 3, article 1469, 2013.

[38] S. Ju, S. Jeong, Y. Kim et al., "Experimental demonstration of surface plasmon resonance enhancement of the tapered optical fiber coated with Au/Ti thin film," Journal of Non-Crystalline Solids, vol. 383, pp. 146-152, 2014.

[39] R. Jarzebinska, S. Korposh, S. James, W. Batty, R. Tatam, and S.-W. Lee, "Optical gas sensor fabrication based on porphyrin-anchored electrostatic self-assembly onto tapered optical fibers," Analytical Letters, vol. 45, no. 10, pp. 1297-1309, 2012.

[40] L. Marques, F. U. Hernandez, S. W. James et al., "Highly sensitive optical fibre long period grating biosensor anchored with silica core gold shell nanoparticles," Biosensors and Bioelectronics, vol. 75, pp. 222-231, 2016.

[41] M. Fujihira, Y. Tani, M. Furugori, U. Akiba, and Y. Okabe, "Chemical force microscopy of self-assembled monolayers on sputtered gold films patterned by phase separation," Ultramicroscopy, vol. 86, no. 1-2, pp. 63-73, 2001.

[42] V. Ruddy, B. D. MacCraith, and J. A. Murphy, "Evanescent wave absorption spectroscopy using multimode fibers," Journal of Applied Physics, vol. 67, no. 10, pp. 6070-6074, 1990.

[43] P. C. Weber, D. H. Ohlendorf, J. J. Wendoloski, and F. R. Salemme, "Structural origins of high-affinity biotin binding to streptavidin," Science, vol. 243, no. 4887, pp. 85-88, 1989.

[44] A. Messica, A. Greenstein, and A. Katzir, "Theory of fiber-optic, evanescent-wave spectroscopy and sensors," Applied Optics, vol. 35, no. 13, pp. 2274-2284, 1996.

[45] Y. Xu, A. Cottenden, and N. B. Jones, "A theoretical evaluation of fibre-optic evanescent wave absorption in spectroscopy and sensors," Optics and Lasers in Engineering, vol. 44, no. 2, pp. 93101, 2006.

[46] D. G. Kinniburgh, "General purpose adsorption isotherms," Environmental Science and Technology, vol. 20, no. 9, pp. 895904, 1986.

[47] S. Maguis, G. Laffont, P. Ferdinand et al., "Biofunctionalized tilted Fiber Bragg Gratings for label-free immunosensing," Optics Express, vol. 16, no. 23, pp. 19049-19062, 2008.

[48] J. Vial and A. Jardy, "Experimental comparison of the different approaches to estimate LOD and LOQ of an HPLC method," Analytical Chemistry, vol. 71, no. 14, pp. 2672-2677, 1999. 
[49] Z. Wang, J. R. Heflin, K. Van Cott, R. H. Stolen, S. Ramachandran, and S. Ghalmi, "Biosensors employing ionic self-assembled multilayers adsorbed on long-period fiber gratings," Sensors and Actuators B: Chemical, vol. 139, no. 2, pp. 618-623, 2009.

[50] H. Tazawa, T. Kanie, and M. Katayama, "Fiber-optic coupler based refractive index sensor and its application to biosensing," Applied Physics Letters, vol. 91, no. 11, Article ID 113901, 2007.

[51] S. V. Kergaravat, G. A. Gómez, S. N. Fabiano, T. I. Laube Chávez, M. I. Pividori, and S. R. Hernández, "Biotin determination in food supplements by an electrochemical magneto biosensor," Talanta, vol. 97, pp. 484-490, 2012.

[52] C. $\mathrm{Wu}$ and Q.-H. Xu, "Stable and functionable mesoporous silica-coated gold nanorods as sensitive localized surface plasmon resonance (LSPR) nanosensors," Langmuir, vol. 25, no. 16, pp. 9441-9446, 2009.

[53] I. Pastoriza-Santos, J. Pérez-Juste, and L. M. Liz-Marzán, “Silicacoating and hydrophobation of CTAB-stabilized gold nanorods," Chemistry of Materials, vol. 18, no. 10, pp. 2465-2467, 2006. 


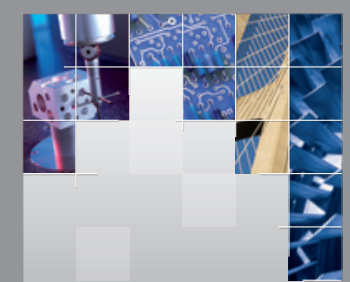

\section{Enfincering}
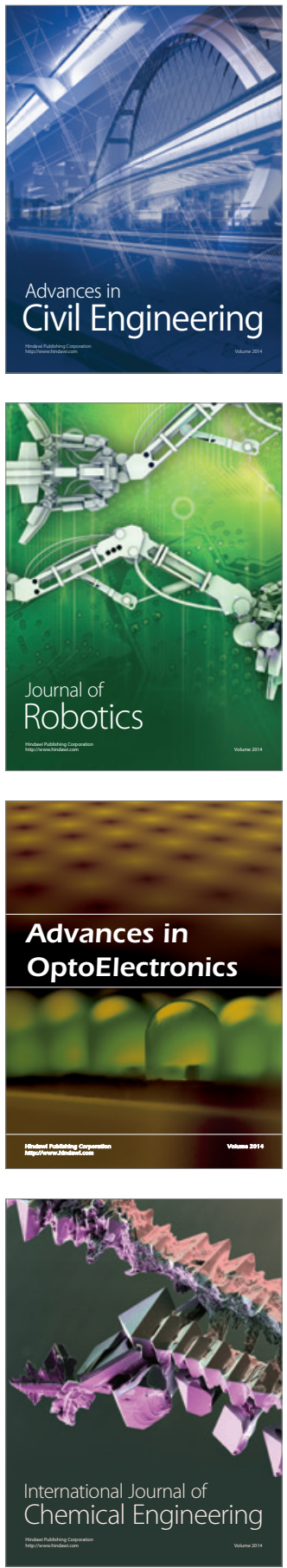

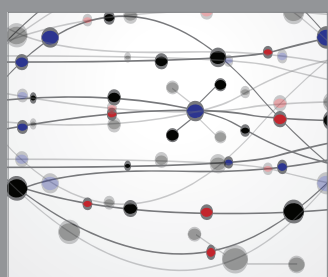

The Scientific World Journal

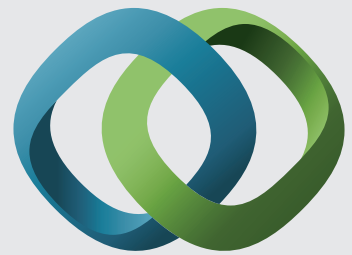

\section{Hindawi}

Submit your manuscripts at

http://www.hindawi.com
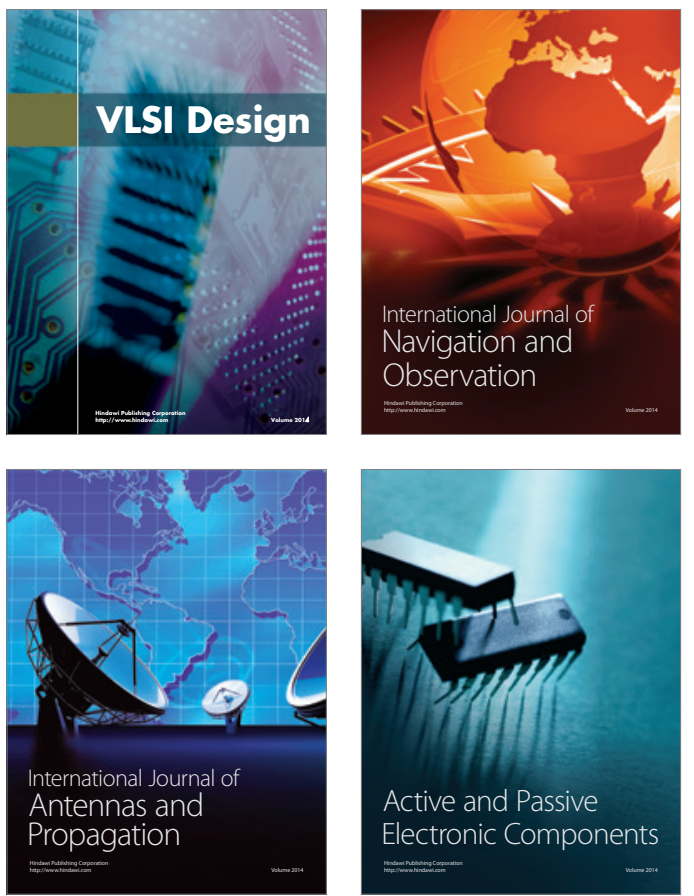
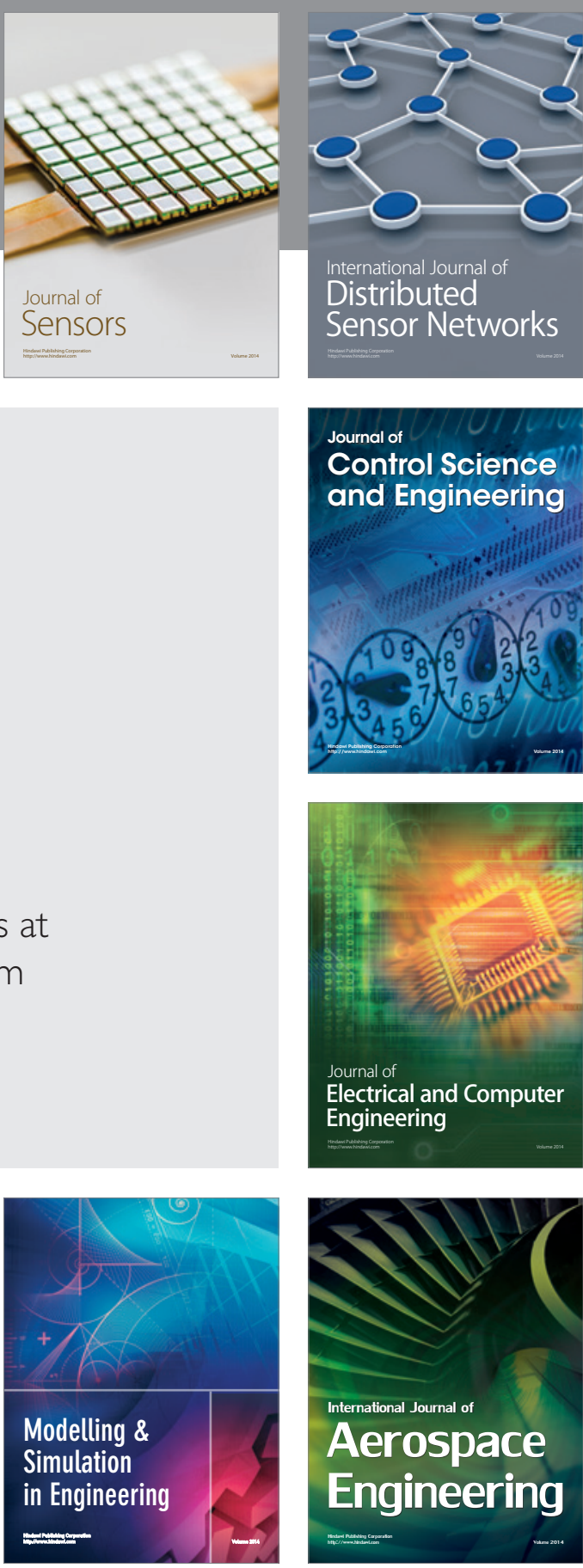

International Journal of

Distributed

Sensor Networks

Journal of

Control Science

and Engineering
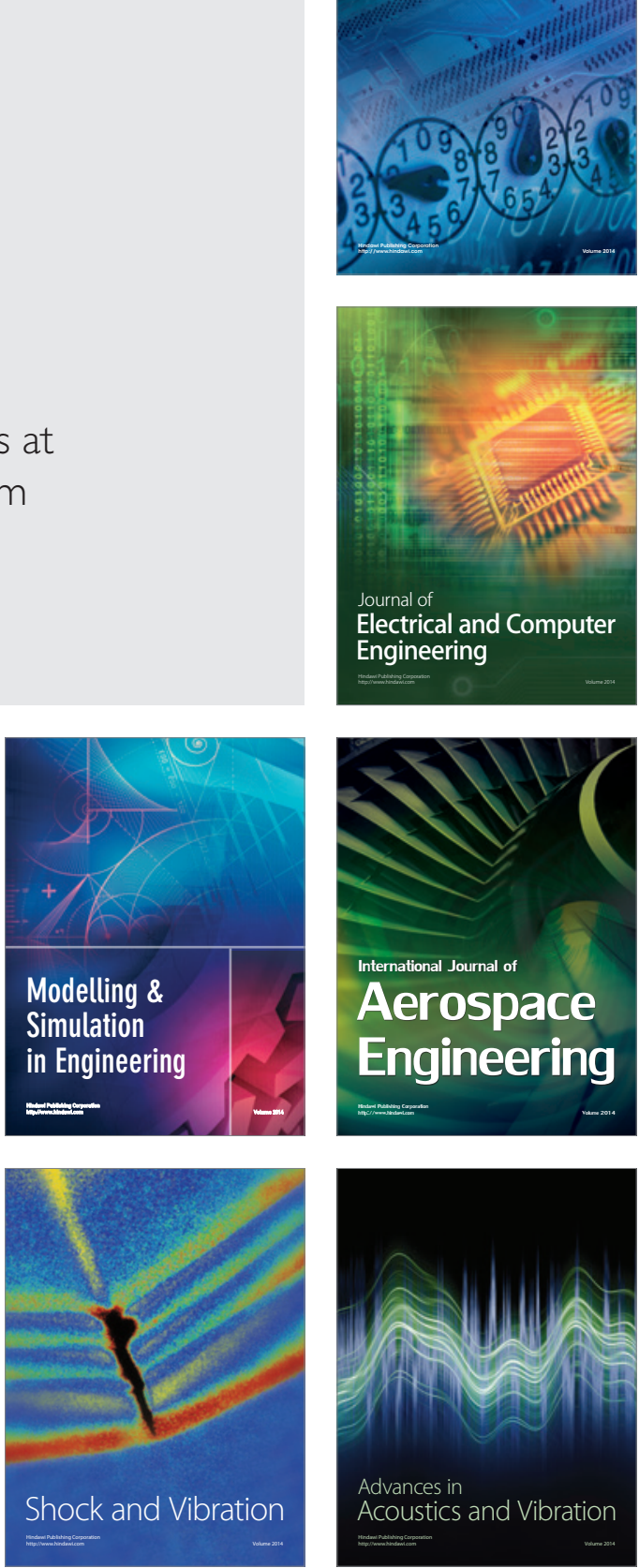